\title{
The toxicity of certain cereal proteins in coeliac disease
}

\author{
H. J. CORNELL ${ }^{1}$ AND R. R. W. TOWNLEY \\ From the Department of Gastroenterology, Royal Children's Hospital, Melbourne, Australia
}

SUMMARY Gliadins from wheat, rye, and oats, and from wheat glutenin were digested with pepsin, trypsin, and pancreatin and the products (PTC digests) chromatographed on sulphopropyl (SP) Sephadex.

Fractions eluted near neutral $\mathrm{pH}$ from wheat, rye, and oats gliadin digests all had very similar amino acid composition, although the oats fraction was higher in sulphur-containing amino acids. The major amino acids present in all were glutamine/glutamic acid and proline.

The amount of fraction eluted near neutral $\mathrm{pH}$ from oats gliadin digest was about $13 \%$ of that eluted from digests of wheat and rye gliadins. Moreover, the yield of gliadin from oatmeal was only $0.5 \%$ compared with $2.4 \%$ and $2.8 \%$ from rye and wheat flours respectively.

The amount of fraction eluted from wheat glutenin digest was about $70 \%$ of that obtained from wheat and rye gliadin digests.

The fractions eluted near neutral $\mathrm{pH}$ from all protein digests were defectively digested by remission coeliac mucosa, and D-xylose excretion tests with the fraction from the wheat gliadin digest (fraction 9) indicated that it is harmful to subjects with coeliac disease, whereas the other fractions of this digest gave no such evidence.

The results of the present work indicate that counterpart fractions to fraction 9 obtained from wheat glutenin and rye and oats gliadins may also be important in the aetiology of coeliac disease.

Evidence has recently been put forward (Cornell and Townley, 1973) that the primary abnormality in coeliac disease is a deficiency of a peptidase in the small intestine which is required for complete digestion of wheat gluten. The peptidase in question appears to be, in particular, necessary for complete digestion of fraction 9 , one of 13 fractions obtained by sulphoethyl (SE) Sephadex chromatography of a peptic-tryptic-pancreatinic digest of wheat gliadin. Fraction 9, a group of polypeptides eluted near neutral $\mathrm{pH}$, has been shown to be toxic in vitro to duodenal mucosa from children with coeliac disease (Townley, Bhathal, Cornell, and Mitchell, 1973). An attempt to obtain proof of its toxicity was therefore attempted in this study.

Weijers and van de Kamer (1960) have stated that gluten from wheat, rye, barley, or oats causes symptoms of coeliac disease. Fletcher and McCririck (1958) however, did not observe any ill effects from the inclusion of oats in the diet.

${ }^{1}$ Correspondence to: Dr. H. J. Cornell, University of Birmingham, Institute of Child Health, Francis Road, Birmingham B16 8ET

Received for publication 10 July 1974.
Since wheat, rye, and oats are common items of the diet, we felt that these cereals deserved investigation for the presence of gliadins and polypeptide fractions similar to fraction 9 of the wheat gliadin digest.

Furthermore, as van de Kamer and Weijers (1955) have indicated that wheat glutenin has a milder toxicity than wheat gliadin in coeliac disease, and that it also has a lower amide nitrogen content, a study of differences in chemical composition of these two substances also seemed worthwhile. Bietz and Rothfus $(1970,1971)$ have already shown that enzymic digestion of wheat gliadin and glutenin produced many similar peptides, although there were some characteristic differences such as the positioning of glutamine in the proteins. In the context of the present paper, the investigations applied particularly to yields of polypeptide fractions similar to fraction 9, their amino acid composition, and digestibility by remission coeliac mucosa.

\section{Materials and Methods}

CEREAL PROTEINS

Gliadin was prepared from commercial wheat 
gluten as previously described (Cornell and Townley, 1973).

Wheat glutenin, which separated in the course of preparing the gliadin, was redispersed in $70 \%$ ethanol, $0.01 \mathrm{M}$ with respect to acetic acid, and reprecipitated by increasing the $\mathrm{pH}$ to 6.8 . After determination of the solids content (about $41 \%$ ), an appropriate quantity was set aside for enzymic digestion.

Rye gliadin was prepared from South Australian ryecorn (supplied and milled by courtesy of the Department of Agriculture, Victoria) by dispersion of the flour $(100 \mathrm{~g})$ in the ethanol-acetic acid mixture $(300 \mathrm{ml})$, after which the gliadin was separated by precipitation with absolute ethanol in the normal way and lyophilized.

Oats gliadin was prepared in the same way from finely ground oatmeal.

\section{PROTEIN DIGESTS AND FRACTIONATION PROCEDURE}

Pepsin, trypsin, and pancreatin (Cotazym, Organon Inc, New Jersey, USA) digested wheat gliadin (PTC digest) and fractions thereof were prepared as described by Cornell and Townley (1973). The same technique was used with rye and oats gliadins. With wheat glutenin, the time of digestion with pepsin was four hours, otherwise the procedure was the same. SP Sephadex (Pharmacia AB, Uppsala, Sweden) which has superseded SE Sephadex, was used for all fractionations.

\section{ANALYSIS OF PROTEINS AND FRACTIONS OF \\ THE PROTEIN DIGESTS}

Fractions of the digests were analysed for amide and total nitrogen and for amino acids as previously reported (Cornell and Townley, 1973). Amide and total nitrogen determinations were also performed on the proteins and their parent cereals.

\section{MUCOSAL INCUBATION STUDIES}

Four children who had initially typical clinical and histological features of coeliac disease were re- investigated by duodenal biopsy (Townley and Barnes, 1973) after four months to one year on a gluten-free diet. Portions of biopsy material from four children, not diagnosed as having coeliac disease, who were being investigated for recurrent diarrhoea, were used as controls.

The biopsy tissue was homogenized, portions from the coeliacs and the controls were incubated with each of the various fractions, and the filtrates subjected to high voltage electrophoresis in order to detect undigested peptides (Cornell and Townley, 1973).

D-XYLOSE EXCRETION (SAMMONS, MORGAN, FRAZER, MONTGOMERY, PHILIP, AND

PHILLIPS, 1967) STUDIES

Four children aged between 8 and 17 years, diagnosed as having coeliac disease, but who had since been on a gluten-free diet for at least two years, were each given D-xylose $(5 \mathrm{~g})$ in water and the two-hour urinary excretion was determined (Roe and Rice, 1948). They were then fed the pooled desalted fractions, excluding fraction 9, of the PTC wheat gliadin digest obtained from a weight of gliadin equivalent to $370 \mathrm{mg} / \mathrm{kg}$ body weight. D-xylose excretion over two hours was repeated 24 hours and 48 hours after the initial dose. One patient (M.P.) was given an additional dose of these fractions one week before the test in order to see if sensitization was a prerequisite.

Five days later, a second test was commenced using fraction 9 of this digest.

Two children (P.U. and J.B.) were also tested two months later using fraction 9 from the wheat glutenin digest. Tests were run on the same basis as the fractions of the gliadin digest, since the yield of glutenin from gluten is approximately equal to that of gliadin.

Two normal children, aged 14 and 16, each of whom had previously volunteered for a duodenal biopsy, also volunteered for a D-xylose test in which they were given the whole digest of wheat gliadin on the above dosage basis.

\begin{tabular}{llll}
\hline Product & Percentage Yield & Percentage Amide $N$ & $\% \frac{\text { Amide } N}{\text { Total } N}$ \\
\hline Wheat flour & - & $0 \cdot 34$ & $20 \cdot 1$ \\
Rye flour & - & $0 \cdot 30$ & $20 \cdot 9$ \\
Oatmeal & - & $0 \cdot 22$ & 14.4 \\
Wheat gliadin & $2 \cdot 8$ & $4 \cdot 03$ & $24 \cdot 2$ \\
Wheat glutenin & $2 \cdot 2$ & $2 \cdot 84$ & $18 \cdot 0$ \\
Rye gliadin & $2 \cdot 4$ & $2 \cdot 95$ & $21 \cdot 1$ \\
Oats gliadin & $0 \cdot 5$ & $3 \cdot 07$ & 20.6 \\
\hline
\end{tabular}

Table I Yields of the various cereal proteins and their amide nitrogen contents ${ }^{1}$

${ }^{1}$ Cereal flours are included for comparison. 


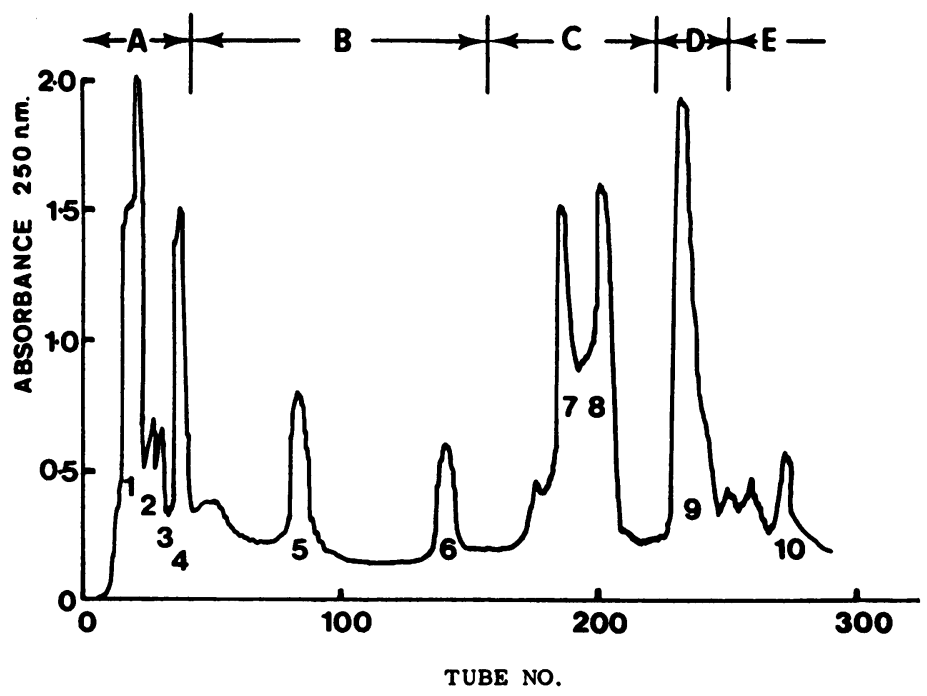

Fig 1 Elution profile from chromatography of PTC wheat gliadin digest on SP Sephadex (C-25).

Elution programme:

$0.005 M$ phosphate buffer $p H 3.1(A)$ $0.02 M$ phosphate buffer pH 5.4 (B) Approximately linear $\mathrm{pH}$ gradient to $\mathrm{pH} 6 \cdot 2(\mathrm{C})$

$0.02 M$ phosphate buffer $\mathrm{pH} 8.0$ (D) $0.02 M$ phosphate buffer containing $0 \cdot 25 \mathrm{M} \mathrm{NaCl}$ (E)

Duration of buffer indicated by letters $A$ to $E$ within arrows.

Rate: $\quad 12 \mathrm{ml} / \mathrm{cm}^{2} / \mathrm{hr}$

Fraction volume: $25 \mathrm{ml}$

Column dimensions $55 \times 3.7 \mathrm{~cm}$

Results

YIELDS AND AMIDE NITROGEN CONTENTS OF THE VARIOUS CEREAL PROTEINS

These are seen in table I. The yield of gliadin from oatmeal is only $t$ of that obtained from wheat flour. The percentage of amide nitrogen of the total nitrogen $\left(\% \frac{\text { amide } N}{\text { total } N}\right)$ in oats gliadin is greater than that of the parent meal.
The yield of rye gliadin was similar to that of wheat gliadin, but, unlike wheat gliadin, there was virtually no difference between the $\% \frac{\text { amide } N}{\text { total } N}$ of the gliadin obtained and that of the rye flour.

The $\% \frac{\text { amide } \mathrm{N}}{\text { total } \mathrm{N}}$ of the wheat gliadin was highest of all the gliadins and higher than that of wheat flour and wheat glutenin.

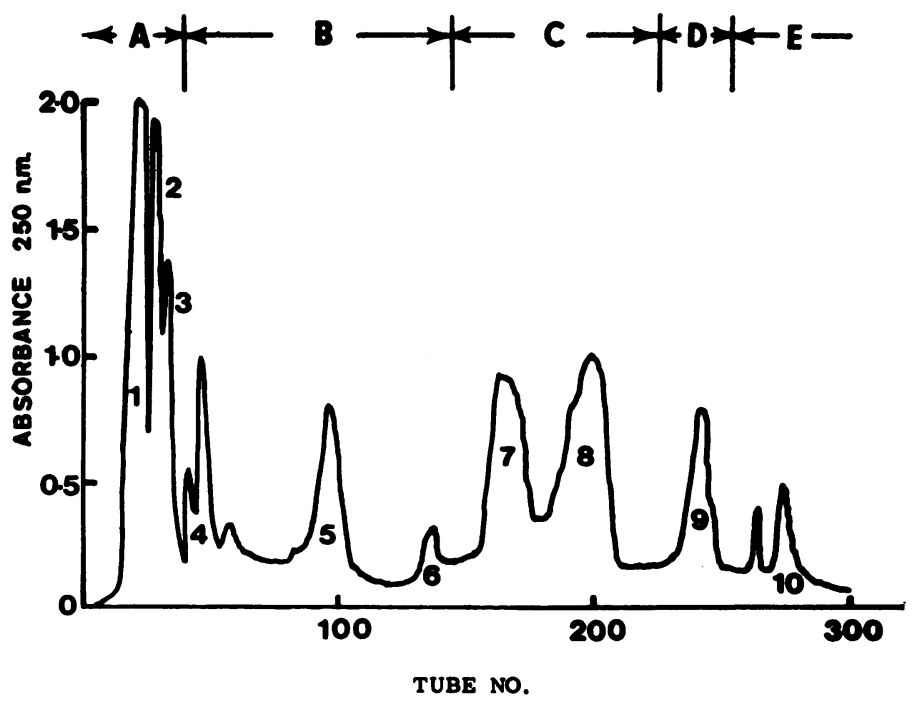

Fig 2 Elution profile from chromatography of PTC wheat glutenin digest on SP Sephadex (C-25). Procedure as for figure 1. 


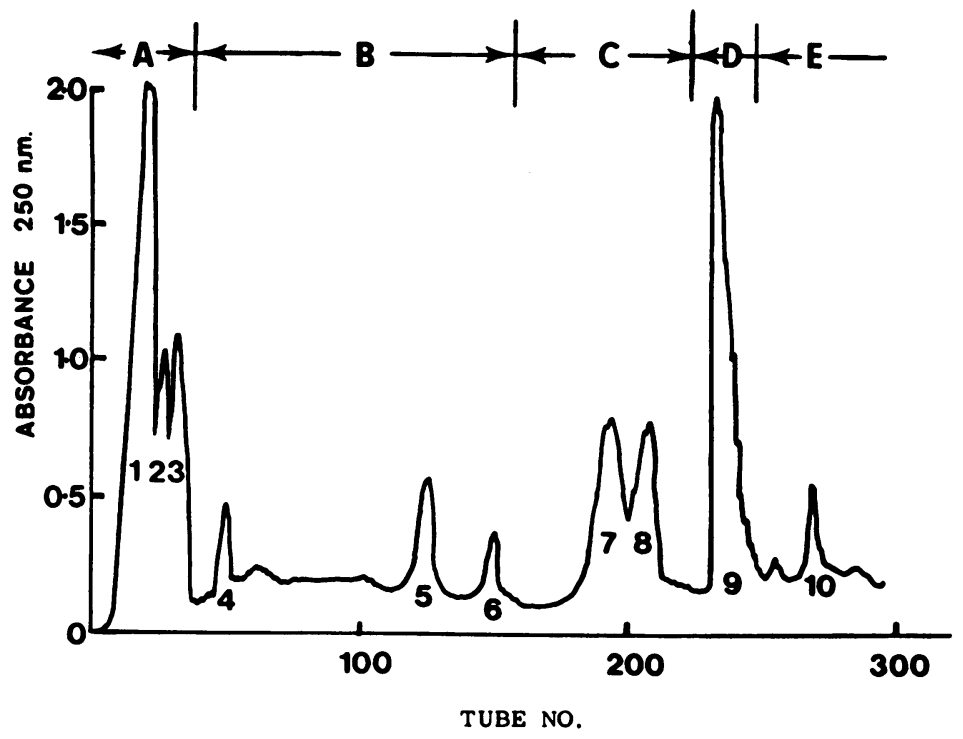

Fig 3 Elution profile from chromatography of PTC rye gliadin digest on SP Sephadex $(C-25)$. Procedure as for figure 1.

\section{CHROMATOGRAPHY OF PTC DIGESTS OF} WHEAT GLIADIN, WHEAT GLUTENIN, AND RYE AND OATS GLIADINS

Elution profiles from chromatography of the four cereal protein digests are shown in figures 1-4.

The profiles from wheat gliadin and rye gliadin digests were similar and comparable peaks were obtained near neutral pH. However, the peak obtained from wheat glutenin near neutral $\mathrm{pH}$ was somewhat smaller and that from oats gliadin was very small.

\section{ANALYSIS OF FRACTIONS OF THE PROTEIN DIGESTS}

Table II shows the yields (as \% of total nitrogen applied) of each of the fractions eluted near neutral $\mathrm{pH}$, together with their amide nitrogen contents. Only fractions 9 are listed, as these were the only fractions eluted near neutral $\mathrm{pH}$ without the addition of salt to the eluant.

The amounts of fractions eluted near neutral $\mathrm{pH}$ from digests of wheat gliadin and rye gliadin were similar (approximately $8 \%$ of total $\mathrm{N}$ applied)

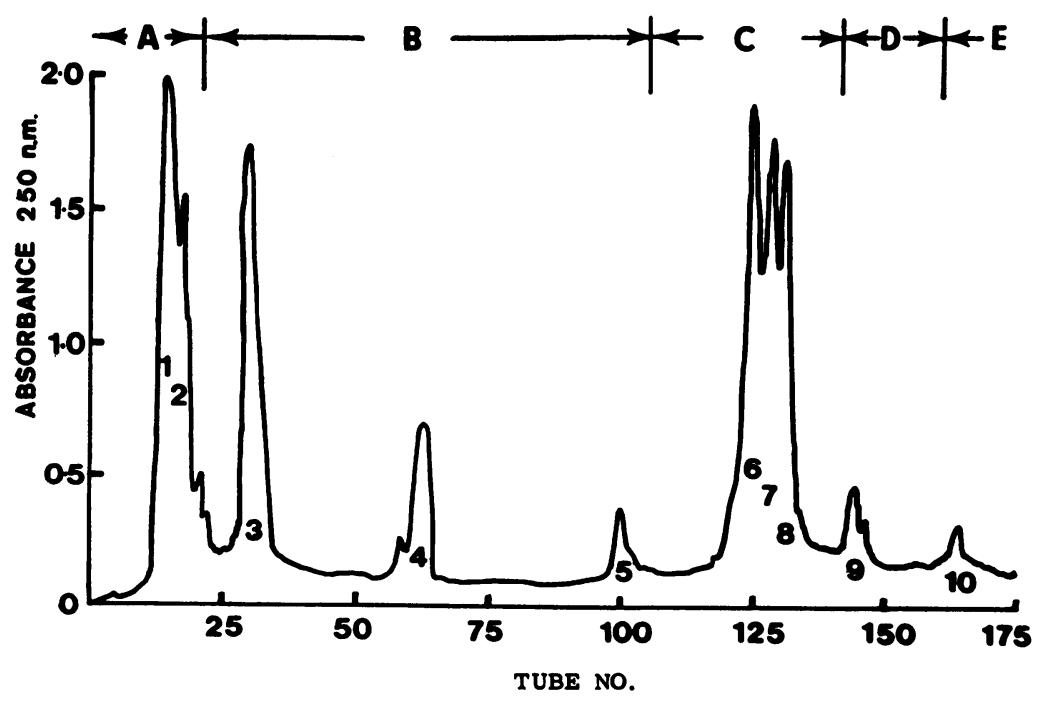

Fig 4 Elution profile from chromatography of PTC oats gliadin digest on SP Sephadex (C-25).

Fraction volume $15 \mathrm{ml}$ Column dimensions $40 \times$ $2.5 \mathrm{~cm}$ Other details as for figure 1. 


\begin{tabular}{llll}
\hline Protein Digest & $p H$ Range Eluted & $\begin{array}{l}\text { Percentage of } \\
\text { Total Nitrogen Applied }\end{array}$ & $\begin{array}{l}\text { Amide } N \\
\text { Total N }\end{array}$ \\
\hline Wheat gliadin & $6 \cdot 1-7 \cdot 3$ & $7 \cdot 9$ & $20 \cdot 0(31 \cdot 7)^{2}$ \\
Wheat glutenin & $6 \cdot 1-7 \cdot 2$ & $5 \cdot 6$ & $18 \cdot 1(29 \cdot 8)$ \\
Rye gliadin & $6 \cdot 2-7 \cdot 4$ & $7 \cdot 4$ & $19 \cdot 0(30 \cdot 4)$ \\
Oats gliadin & $6 \cdot 4-7 \cdot 5$ & $1 \cdot 0$ & Not done (28.7)
\end{tabular}

Table II Yields and amide nitrogen contents of fractions eluted in the neutral $\mathrm{pH}$ region (fractions 9 ) from chromatography of PTC cereal protein digests on SP Sephadex $(C-25)^{1}$

'Phosphate buffer system: elution rate $12 \mathrm{ml} / \mathrm{cm}^{2} / \mathrm{hr}$

${ }^{2}$ Figures in parentheses are results for fraction 1 of these digests.

but the amount eluted from glutenin digest was somewhat lower $(5.6 \%$ of total $\mathrm{N}$ applied). In the case of oats gliadin digest the amount was considerably lower $(1 \%)$ representing only $0.005 \%$ of the oatmeal. By comparison, fraction 9 of wheat gliadin digest represents $0.22 \%$ of the wheat flour. The actual yield of the desalted fraction from oats gliadin digest was only about $1 / 100$ of that from wheat gliadin digest after the same treatment.

Fractions eluted near neutral $\mathrm{pH}$ were not as high in amide nitrogen (apart from the oats gliadin fraction, which was not tested due to insufficient yield) as those fractions eluted at acidic $\mathrm{pH}$ values. In the case of each protein tested, fraction 1 gave the highest $\% \frac{\text { amide } \mathrm{N}}{\text { total } \mathrm{N}}$ of all fractions.

Table III shows the amino acid analyses of the fractions eluted at neutral $\mathrm{pH}$. All fractions contain large amounts of glutamine/glutamic acid and proline, and otherwise are generally very similar. The exception was that sulphur-containing amino acids were also present in significant quantities in the case of the oats gliadin fraction, as were also asparagine/aspartic acid and valine.

\section{MUCOSAL INCUBATION STUDIES}

In addition to undigested peptides being detected after incubation of remission coeliac mucosa with fraction 9 of the wheat gliadin digest, noticeable residues were observed in the case of fraction 9 of both the rye and the wheat glutenin digests, and, to a lesser extent, fraction 9 of the oats gliadin digest. These residues are seen as stains between the slow moving pyroglutamic acid and the glutamine markers. No significant residues were detected after digestion of these fractions with control mucosa. With the more acidic fractions (1-4), small amounts of residues of low electrophoretic mobility were seen, but there were no apparent differences between the intensities of stains from digestions with coeliac and control mucosa.

Figure 5 typifies the results obtained with mucosal digests of fraction 9 from the various protein digests

\begin{tabular}{|c|c|c|c|c|}
\hline \multirow[t]{2}{*}{ Amino Acid } & \multicolumn{4}{|l|}{ Fraction 9} \\
\hline & Wheat Gliadin & Wheat Glutenin & Rye Gliadin & Oats Gliadin \\
\hline Asp & 3.46 & 3.50 & $4 \cdot 70$ & 8.44 \\
\hline Thr & $3 \cdot 28$ & $3 \cdot 23$ & 3.51 & 1.63 \\
\hline Ser & 5.89 & $6 \cdot 48$ & 5.60 & 2.89 \\
\hline Glu & 30.72 & 30.83 & $28 \cdot 47$ & 22.83 \\
\hline Pro & 15.03 & 14.02 & 16.62 & $13 \cdot 20$ \\
\hline Gly & 3.06 & $4 \cdot 14$ & 5.82 & 380 \\
\hline Ala & $4 \cdot 17$ & 3.09 & $4 \cdot 19$ & 5.07 \\
\hline$\frac{1}{2}$ Cys & Nil & $3 \cdot 41$ & $3 \cdot 21$ & 10.76 \\
\hline $\mathrm{Val}$ & 5.85 & $6 \cdot 43$ & 5.61 & 8.36 \\
\hline Met & $1 \cdot 16$ & 2.90 & 1.61 & $4 \cdot 10$ \\
\hline Ileu & $5 \cdot 21$ & $3 \cdot 30$ & $2 \cdot 47$ & 2.80 \\
\hline Leu & $7 \cdot 15$ & 7.07 & $4 \cdot 78$ & 4.76 \\
\hline Tyr & 1.34 & 1.05 & 1.09 & 3.90 \\
\hline Phe & 2.09 & 2.09 & $2 \cdot 69$ & 0.76 \\
\hline Lys & 2.57 & $2 \cdot 20$ & $2 \cdot 10$ & $3 \cdot 30$ \\
\hline His & 6.56 & $5 \cdot 10$ & 5.07 & 2.54 \\
\hline & $1 \cdot 27$ & $1 \cdot 16$ & $2 \cdot 46$ & 0.86 \\
\hline Unidentified & $1 \cdot 19$ & - & -70 & - \\
\hline Total & $100 \cdot 00$ & $100 \cdot 00$ & 100.00 & 100.00 \\
\hline
\end{tabular}

Table III Amino acid analyses of fractions eluted in the neutral pH region (fractions 9 ) from chromatography of PTC cereal protein digests on SP Sephadex $(C-25)$ 


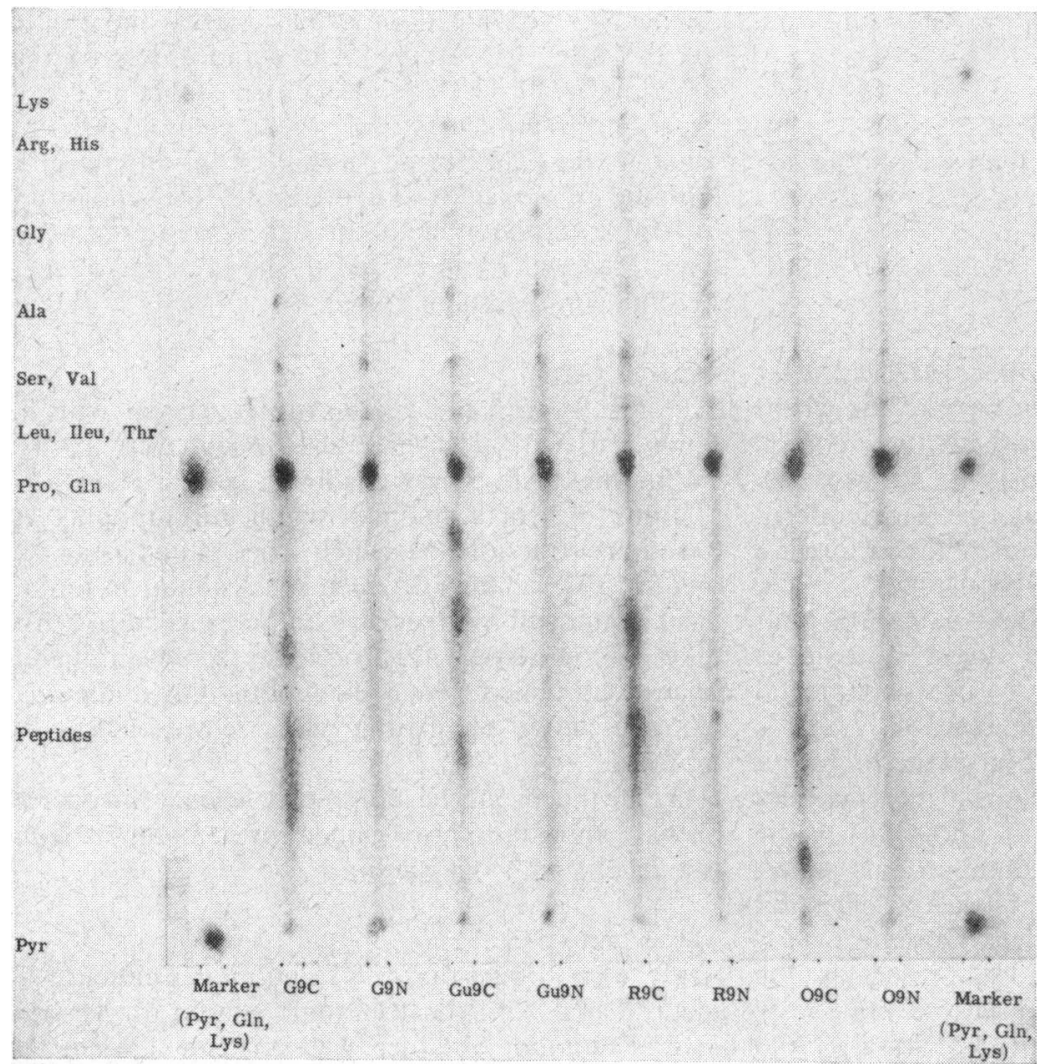

Fig 5 HVE of remission coeliac mucosal digests of fractions 9 from PTC digests of various cereal proteins.

Buffer: acetic-formic acidwater (pH 1.9)

Voltage: $70 \mathrm{~V} / \mathrm{cm}$ Time 35 minutes

Paper: Whatman 3 MM.

Stain: $K l$-starch after chlorination

G9 = fraction 9 of wheat

gliadin digest

Gu9 = fraction 9 of wheat

glutenin digest

$R 9=$ fraction 9 of rye

gliadin digest

$09=$ fraction 9 of oats

gliadin digest

After the above, $C$ stands for coeliac mucosal digestion, $N$ stands for normal mucosal digestion.

and clearly shows that these particular fractions are incompletely digested by remission coeliac mucosa.

\section{D-XYLOSE EXCRETION STUDIES}

Table IV shows that reductions in urinary excretion of D-xylose were obtained with all four coelaic patients in remission after having been given fraction 9 of the PTC wheat gliadin digest. In two cases (P.U., J.B.), notable reductions (21-24\%) were observed even at 24 hours after ingestion and the results at 48 hours provide strong evidence of toxicity.

No significant change in D-xylose excretion occurred following ingestion of the other fractions of the wheat gliadin digest, even in the patient who had had a prior dose. Similar results were obtained

\begin{tabular}{|c|c|c|c|}
\hline \multirow[t]{2}{*}{ Patient } & \multicolumn{3}{|c|}{$\begin{array}{l}\text { Percentage Change in D-xylose Excreted in Urine } \\
\text { ( } 48 \text { hours after ingestion of test substance) }\end{array}$} \\
\hline & $\begin{array}{l}\text { Other Fractions except } \\
\text { Fraction } 9\end{array}$ & Fraction 9 & Whole Digest \\
\hline $\begin{array}{l}\text { Coeliac P.U. } \\
\text { Coeliac J.B. } \\
\text { Coeliac T.P. } \\
\text { Coeliac M.P. } \\
\text { Normal S.T. } \\
\text { Normal E.T. }\end{array}$ & $\begin{array}{l}+9.3 \\
+9.6 \\
+5.7 \\
-4.9 \\
\text { Not done } \\
\text { Not done }\end{array}$ & $\begin{array}{l}-53.9 \\
-35 \cdot 7 \\
-14 \cdot 0 \\
-21 \cdot 2 \\
\text { Not done } \\
\text { Not done }\end{array}$ & $\begin{array}{l}\text { Not done } \\
\text { Not done } \\
\text { Not done } \\
\text { Not done } \\
-2 \cdot 0 \\
+2 \cdot 1\end{array}$ \\
\hline Means & +4.9 & $-31 \cdot 2$ & +0.1 \\
\hline
\end{tabular}

Table IV Results of D-xylose excretion test after feeding fraction 9 and the other combined fractions of the PTC wheat gliadin digest ${ }^{1}$

${ }^{1}$ Paired $t$ test on differences between results of fraction 9 (wheat gliadin) and other fractions with coeliacs gave $P<0.01$ (single tail). 
when the whole digest was given to the two normal children.

Preliminary results on fraction 9 of the wheat glutenin digest indicate that this fraction is also toxic, although perhaps less so than its counterpart fraction from wheat gliadin.

\section{Discussion}

\section{WHEAT GLIADIN}

Previous work (Cornell and Townley, 1973; Townley et al, 1973) has shown that fraction 9 of the wheat gliadin digest is incompletely digested by coeliac mucosa of patients in remission, consistently prevents morphological recovery of coeliac duodenal mucosa from patients with untreated coeliac disease in vitro, and is active to rat-liver lysosomes.

The demonstration, by D-xylose excretion, that fraction 9 of the PTC gliadin digest is toxic to children with coeliac disease, is of fundamental importance to these studies. This fraction, which is eluted at near neutral $\mathrm{pH}$ with phosphate buffer on SE or SP Sephadex, contains several polypeptides which are present to the extent of about $8 \%$ of the total nitrogen applied to the column. Thus a link has now been established between defective digestion and the toxicity of gluten in coeliac disease.

Pyrrolidone carboxylyl peptides, present in the other fractions (mainly fraction 1) and previously thought (Bronstein, Haeffner, and Kowlessar, 1966) to be toxic in coeliac disease, did not affect D-xylose excretion. This is in keeping with the results of our mucosal digestion experiments (Cornell and Townley, 1973) and those of Woodley (1972) who showed no deficiency of pyrrolidone carboxylyl peptidase in coeliac intestinal mucosa. Fraction 1 had the highest

percentage of amide nitrogen $\left(\right.$ as $\left.\% \frac{\text { amide } N}{\text { total } N}\right)$ of all fractions. In the case of the wheat protein fractions, these figures are related mainly to the percentage of glutamine present. The latter is thus not the only factor (relating to composition) involved in toxicity.

\section{WHEAT GLUTENIN}

The finding of a somewhat lower amount of fraction eluted in the region of neutral pH in PTC wheat glutenin digest (compared to the wheat gliadin digest) is in keeping with the relatively lower toxicity of glutenin elsewhere reported (van de Kamer and Weijers, 1955).

The results of preliminary tests with this fraction of wheat glutenin (fraction 9) in the D-xylose test indicates some degree of toxicity. With this fraction, as perhaps even with the wheat gliadin fraction, higher or multiple dosage may clarify the results of the test. The amino acid composition of this fraction is almost identical with its counterpart fraction (fraction 9) from wheat gliadin, differing only in that the former is higher in sulphur-containing amino acids. Furthermore, the finding of defective digestion with this fraction supports the view that toxicity is related to the presence of such fractions in digests of gluten.

\section{RYE GLIADIN}

The results with rye gliadin are consistent with its known toxicity in coeliac disease and were similar to findings with wheat gliadin in several ways.

Both digests contained significant amounts of fractions (fractions 9) which were eluted near the neutral $\mathrm{pH}$ range and which were similar in amino acid composition. Fraction 9 of the rye gliadin digest, like its counterpart fraction from the wheat gliadin digest, contained noticeable amounts of undigested peptides after incubation with remission coeliac mucosa.

Thus the proposed enzyme deficiency in coeliac disease appears to have gained further support from the results with rye gliadin.

\section{OATS GLIADIN}

Only a small quantity of a fraction was eluted near neutral pH from the PTC oats gliadin digest. The overall amount obtained was very small when the yield of oats gliadin itself is taken into account. However, the presence of even a small amount of a fraction thought to be associated with toxicity suggests that oats should be excluded from a diet regarded as strictly gluten-free. The possibility exists that there may be certain individuals who are sensitive even to these low levels of toxic components.

The amino acid analysis of this fraction (fraction 9) was similar to that of the wheat gliadin fraction (except for higher sulphur-containing amino acids and asparagine/aspartic acid) and there was incomplete mucosal digestion of this fraction, similar to that seen with the fractions 9 of the other proteins.

Further experiments using organ culture may help to establish the toxicity of fractions of the oats gliadin digest as oral feeding tests on products from a material of such low toxicity would be necessarily very protracted.

\section{References}

Bietz, J. A., and Rothfus, J. A. (1970). Comparison of peptides from wheat gliadin and glutenin. Cereal Chem., 47, 381-392.

Bietz, J. A., and Rothfus, J. A. (1971). Differences in amino acid sequences of gliadin and glutenin. Cereal Chem., 48, 677-690.

Bronstein, H. D., Haeffner, L. J., and Kowlessar, O. D. (1966) Enzymatic digestion of gliadin: The effect of the resultant peptides in adult coeliac disease. Clin. chim. Acta, 14, 141-155.

Cornell, H. J., and Townley, R. R. W. (1973). Investigation of possible 
intestinal peptidase deficiency in coeliac disease. Clin. chim. Acta, 43, 113-125.

Fletcher, R. F., and McCririck, M. Y. (1958). Gluten-free diets. Brit. med. J., 2, 299-301.

van de Kamer, J., and Weijers, H. A. (1955). Coeliac disease. V. Acta paediat. (Uppsala), 44, 465-469.

Roe, J. H., and Rice, E. W. (1948). A photometric method for the determination of free pentoses in animal tissues. J. biol. Chem., 173, 507-512.

Sammons, H. G., Morgan, D. B., Frazer, A. C., Montgomery, R. D., Philip, W. M., and Phillips, M. J. (1967). Modification in the xylose absorption test as an index of intestinal function.
Gut, 8, 348-353.

Townley, R. R. W., and Barnes, G. L. (1973). Intestinal biopsy in childhood. Arch. Dis. Childh., 48, 480-482.

Townley, R. R. W., Bhathal, P. S., Cornell, H. J., and Mitchell, J. D. (1973). Toxicity of wheat gliadin fractions in coeliac disease. Lancet, 1, 1363-1364.

Weijers, H. A., and van de Kamer, J. H. (1960). Some biochemical investigations into the cause of wheat sensitivity in coeliac disease. Gastroenterology, 38, 587-591.

Woodley, J. F. (1972). Pyrrolidonecarboxylyl peptidase activity in normal intestinal biopsies and those from coeliac patients. Clin. chim. Acta, 42, 211-213. 